\title{
El efecto particular del intrusismo en Cirugía Plástica y las reacciones médico legales obligadas - Parte I.
}

\author{
The particular effect of the intrusion in Plastic Surgery and the forced \\ medicolegal reactions - Part I.
}

\author{
Guillermo Peña Cabús ${ }^{1}$
}

REVISTA ARGENTINA DE CIRUGÍA PLÁSTICA 2018;24(3):138-139. DOI/10.32825/RACP/201803/0138-0139

Caso \#1. La abogada ofrece aplicar "botox" a un precio muy cómodo.

Caso \#2. La enfermera y masajista hace aumento mamario bilateral inmediato. Utiliza con éxito (temporal al menos) solución salina al $0.9 \%$ más una ampolleta de ácido hialurónico.

Por supuesto estos servicios no se discuten y se acepta o tolera el resultado obtenido para no desvelar la necedad e ingenuidad personal del afectado.

El intrusismo no médico (N-Md) puede en ocasiones ser un gran problema, para la población de influencia, sin embargo no lo es en general para la Especialidad de Cirugía Plástica. Gastar munición de control y esfuerzo no está indicado habitualmente en estos casos. El intrusismo $\mathrm{N}-\mathrm{Md}$ en realidad no es algo nuevo, no obstante lo cual, en la actualidad, se le ha dado esa connotación creándose alarma no justificada.

El comportamiento actual de grupos sociales lanzados a la búsqueda de alteraciones anatómicas personales por consideraciones de mejor apariencia sin importar la fuente de origen y, por otro lado, la creciente oferta de esos servicios, se han encontrado entre sí. A sabiendas de que el público está enterado de la existencia de una especialidad médica con el entrenamiento necesario para ello, persiste en continuar por el elaborado encanto de la ruta de sustitución fácil, aun sabiendo que es probable que sea de riesgo personal y no desconocido. El crecimiento del intrusismo N-Md particularmente en procedimientos cosméticos y algunos estéticos (que desafortunadamente con demasiada frecuencia se confunde el significado y su aplicación),

\section{San Pedro Sula, Honduras}

Correspondencia: Guillermo Peña Cabús. revista@sacper.org.ar

El autor no declara conflictos de intereses. aparentemente se posiciona como algo irrefrenable en este momento. Crea confusión al mezclarse dentro de nuestras tradicionales filas y afecta o daña consecuentemente la reputación de nuestra Especialidad. Daño a la reputación profesional es nuestra posición a considerar en caso de conflicto.

Se debe tomar en cuenta el error en que se incurre cuando se plantea el hecho de que el intrusismo N-Md está causando una reducción de oportunidades en nuestra especialidad, lo cual no es cierto. Solamente resulta cierto que al mencionarlo se les eleva el nivel académico a los intrusistas, y eso no les debe corresponder, pero su notoriedad cuando lo hacemos la utilizan de manera atractiva para con sus adeptos o víctimas potenciales.

La legislación existente para el intrusismo en los diferentes países latinoamericanos es muy similar y las leyes para el control necesario están plasmadas, pero no se aplican porque el intrusista en cuestión no tiene el grado de médico. Es por ello que no es susceptible de regulación médica, y en consecuencia se les debe acertadamente posicionar dentro la legislación de los delitos comunes y su proceso legal correspondiente.

En verdad que existen casos aislados de control logrado contra el intrusismo en diferentes países, con resultados considerados como legalmente exitosos. Aunque los efectos de control pueden de alguna manera ser predecibles, esto no se ha demostrado y la marea contaminante del intrusismo sigue bañando todas las playas posibles ante la ya acostumbrada posición general de mera observación, acompañada de una estéril y ruda crítica. Alguien se refirió a ello como "la charlatanería encantadora disfrazada de elegancia”: eso gusta mucho al público tolerante.

La figura legal muy determinante a considerar y que por cierto no es detectada en condiciones habituales es la del tercero aparte. Usualmente se trata de un "empresario" con inversión monetaria, equipo o material, el cual aun conociendo que en ocasiones se va a establecer una actividad lucrativa como fraudulenta, sigue 
con ello sin dar la cara y de surgir conflicto se escabulle en cualquier momento al no ser detectado como partícipe en la relación irregular establecida entre el paciente y el servicio prestado. Para el "empresario" la inversión lucrativa sin recursos de control moral resulta atractiva y generalmente está al margen de las leyes. Sin embargo, por ser el aportante de la estructura facilitadora del servicio, ha incurrido invariablemente en corresponsabilidad legal y pone en juego sus pertenencias personales a manera compensatoria en caso de daños ocasionados. No puede negar ignorancia ni ausencia de responsabilidad una vez ya señalado por los otros actores del proceso. Es entonces necesario investigar y señalar porque también es legalmente vulnerable por daño con dolo de peligro (delitos contra la salud pública entre otros). En estos casos resulta fundamental que se realice la denuncia por parte de las personas agraviadas o sus representantes legales.
El servicio irregular puede haber sido brindado por una persona que no ha completado el entrenamiento formal requerido de Medicina. En estas condiciones los Médicos no tenemos injerencia alguna excepto como figura legal de apoyo técnico aclaratorio en caso necesario. Estamos fuera de la relación contractual que se ha establecido entre el cliente y el proveedor del supuesto servicio tomando en consideración que esa persona (cliente) eligió la manera de conseguir el servicio cuestionado. De no ser médico el que dio el servicio ni el tercero facilitador (socio) involucrado, enfrentarían ambos su participación en una relación de servicio en que surgió conflicto y donde se pueden aplicar figuras legales como fraude, estafa, usurpación de funciones, impericia, etc. y están obligados a satisfacer la compensación del daño a cabalidad además de la penalización correspondiente. 